\title{
Antes de nascer o mundo, de Mia Couto: um soneto desdobrado
}

\author{
Vera MaQuêA \\ Unemat/Fapemat/Capes
}

omo em toda grande literatura é a universalidade do humano que conta mais, não a estreita demanda da paisagem por mais que ela seja importante na configuração da história. A saber o que fizeram Graciliano Ramos e Guimarães Rosa com a ideia de sertão do Brasil, assistimos na prosa encharcada de poesia do moçambicano Mia Couto processo semelhante de elevação do cenário local a dimensões inusitadas de problemáticas plenas de humanidade, encantamento e conflito.

É assim que em Antes de nascer o mundo, ${ }^{1}$ um lugar chamado Jesusalém parece ser hostil até mesmo ao mais sobre-humano dos homens que, expulso para outras paragens, poderia ter extraviado de vez a fé nos homens. Mas, se o deslocamento da terra sagrada para o homem sagrado é mais proposital do que poderíamos prever é justamente pelo desejo de recuperar a confiança nos homens, já que o universo deste novo livro não deixa de dialogar com aquele terreno do primeiro romance de Mia Couto, Terra Sonâmbula (1992), habitado pelo menino Muidinga e pelo velho Tuhair, onde a guerra tende a esterilizar qualquer possibilidade de sonhar e, no entanto, naquele como neste romance a poesia e a escrita aparecem como restauradoras da humanidade do mundo.

O espaço de Terra sonâmbula, que atravessa uma galeria de metáforas topográficas na obra de Mia Couto, passa por 'Vila Longe' e 'Antigamente' de O outro pé da sereia (2006) e se nos apresenta revisitado neste Antes de nascer o mundo, quase trinta anos depois, como um mote de irresoluções: lugar discretamente habitado, distância da civilidade, busca de definições, de formas e de identidades. Esse lugar original, sem os contornos de um mundo previsível, de

1 COUTO, Mia. Antes de nascer o mundo. São Paulo: Companhia das letras, 2009. 
certa maneira torna mais coerente o título da edição brasileira Antes de nascer o mundo, em vista da edição portuguesa Jesusalém, pelo investimento no poder divino da palavra poética de criar mundos e preenchê-los com algum sentido.

O enredo, de uma simplicidade estupefaciente, é a história de um velho homem, Silvestre Vitalício, que leva os filhos da cidade para um lugar remoto a que dá o nome de Jesusalém, inventando para os meninos que o mundo acabou e que não há mais ninguém além deles na terra. Ali, a interdição de rezar, lembrar ou chorar é uma lei para que a "terceira margem" seja possível. Com o tempo, no entanto, Silvestre Vitalício terminará por descobrir que não é possível fugir, apagar ou esquecer o passado porque os homens são constituídos de passado e então seu projeto de Funes invertido é frustrado.

Seduzido pelas possibilidades sempre inacabadas das palavras, do jogo de semantemas e morfemas, da incompletude de combinações dos sistemas linguísticos que articula, o autor moçambicano tem mantido uma produção constante e fiel ao seu tom, ou seja, uma elevada consciência da autoreferencialidade da linguagem que, sendo intensa, às vezes tende a sobrepor-se ao gesto narrativo:

Escutei o farfalhar do peito dele. Parecia que o velho ia desaguar num pranto. De súbito, o sucedido se deflagrou em espanto: meu pai trauteava uma melodia: escutei meu velho cantar! Pela primeira vez, nos meus onze anos, escutei meu velho cantar: Era um trecho triste e a voz dele era como um riachinho feito só de cacimbas. (ANM, p. 181)

Semelhante a ele mesmo, Mia Couto confirma sua dicção literária e desenvolve o trabalho com a linguagem tateando identidades, encostando realidades e buscando um reconhecimento de seu país sem submeter sua literatura àquilo que não seja do interesse da arte. À exceção de O outro pé da sereia, em que o flerte com a história se sobrepõe à fabulação poética da linguagem, criando em seus leitores a expectativa de uma mudança de direção na sua produção dali para diante, o autor moçambicano tem apostado em processos de composição em que o português se criouliza cada vez mais.

A obsessão pela construção da linguagem e a alta consciência das dimensões de sua materialidade poderiam inferir à obra de Mia Couto uma incontestável atitude formalista no melhor dos sentidos, chegando ao limite de produzir um efeito derivante: narrar o inenarrável, chegando à antinarrativa. 
Mas quando propomos a pergunta: é possível escrever um romance para não contar história alguma, onde o fim e o começo sejam apenas um motivo para a linguagem se exercitar, brilhar e aparecer? a resposta surge vigorosa como a ilusão que nos levou a fazê-la. Como ensina Antonio Candido, o externo e o interno estão de tal modo intricados que já não é possível pensar o mundo representado e a linguagem que o configura alheios um ao outro.

Entretanto, reconhecemos que há uma espécie de adiamento da trama, o processamento vagaroso do gesto de narrar retardando de expressa vontade o desenrolar dos acontecimentos. E essa não-narrativa vai estendendo a beleza de uma história que se conta fora da palavra, no dorso escorregadio de expressões poéticas, uma história de lutas políticas que edifica liberdades, ainda não de todo consolidadas.

Mais que em outros romances do autor, o trocadilho neste Antes de nascer 0 mundo aparece como um jogo em que a simplicidade ganha regra e no qual a língua portuguesa é protagonista, delineando a condição de seres atravessados pela vontade de se fixar no mundo, ter um pedaço de chão para se sentir em casa, embora o mundo contemporâneo expulse cada um do conforto de qualquer tipo de raiz: "Vou sem causa, venho sem coisa". (ANM, p. 96). A ambiguidade que reina nesta narrativa através do uso do trocadilho é produzida pela ironia a partir da construção analógico-linguística, sem subterfúgios.

Além do trocadilho, a epígrafe é um outro elemento de composição narrativa que Mia Couto preza e reinventa, expandindo a inserção de vozes no seu texto. Neste último livro as epígrafes são abrangentes e ainda maiores, escandalosamente citantes e deferentes, cujas vozes femininas predominam e onde parecem mover interfaces variadas com um mundo mutante e crível, de libertação e denúncia da condição feminina em fase de superação histórica que se confunde com a terra.

Mas quem quisesse um traço que definisse a escrita de Mia Couto não seria ainda aqui que o encontraria tão fácil. Jesusalém, lugar habitado por homens, é introduzido pela poesia. A escrita com ressonâncias claricianas é adensada por citações de Adélia Prado, Sophia de Mello Breyner Andresen e Hilda Hilst: a existência feminina nas suas variadas dimensões, ao sacar do cotidiano a matéria viva e iluminada de fatos que se revelam inesperadamente, se sobressai na nomeação de personagens como é o caso de Dordalma, contrastando com o universo masculino de Jesusalém. 
Tendo ainda em conta a relação entre o espaço e as personagens deste romance encontramos um discreto paralelismo com a melhor literatura brasileira da década de 30, curiosamente anterior ao formalismo de Clarice Lispector e Guimarães Rosa: impossível, lendo Antes de nascer o mundo, não se lembrar de Vidas secas (1938) de Graciliano Ramos. A similitude não termina no número que constitui a população básica do romance. Lá, temos o Fabiano e a sinhá Vitória, o menino mais velho e o menino mais novo, e a mais humana cachorra ironicamente Baleia. Se os retirantes do nordeste brasileiro, fugindo da seca, pudessem caminhar para fora de suas páginas ou de seu mundo, poderiam viver junto com as personagens que habitam Jesusalém: o lugar é igualmente árido e rude; Silvestre tem dois filhos, vive com eles e com Zacaria Kalash, o militar e a jumenta Jezibela. O tio Aproximado, paradoxalmente, vive longe. Como em Vidas secas, as cinco personagens se debatem pela sobrevivência num lugar que não vai além do alcance de seus olhos, que os mantém a deriva, constantemente, sem ter no horizonte grande possibilidade de repouso. À imensa desumanização da vida, assoma-se a humanização da jumenta Jezibela como ocorre à cachorra Baleia.

Em Antes de nascer o mundo o arranjo familiar será perturbado pela chegada da portuguesa Marta, deslocada à procura de um amante perdido em terras de África. Se Jesusalém é uma inversão da terra sagrada de Jerusalém, lugar "onde Jesus haveria de se descrucificar", não deixa de ser também a repetição de viagens invertidas, das quais Marta é apenas uma personagem modelar.

A mudança de nome - não mudança de qualidade -, faz com que as personagens abdiquem de serem adjetivadas para serem renomeadas: o narrador Mwanito é o Afinador de silêncios; seu irmão, Ntunzi Sombre, é na realidade Olindo Ventura. Incorporações irônicas que não param nesse universo atingem Zacaria Kalash, ex-soldado, agora serviçal de Silvestre Vitalício, no diminutivo o militar é ainda sobrenomeado Sobra, resto de alguma coisa. O pai dos meninos, Silvestre Vitalício é Mateus Ventura, e Orlando Macara, o tio Aproximado. Nem a jumenta escapa de uma nomeação que busca fundir significado e significante: Jezibela é o traço feminino do lugar.

Seduzido pela forma, Mia Couto vem seduzindo também os seus leitores com a procura da poesia. $\mathrm{O}$ ritmo do texto marcado pelos versos fixos do soneto é subvertido tanto nos títulos dos capítulos que compõem cada um dos três "livros" que constituem o romance quanto no conteúdo e na linguagem, 
o que ecoa na escolha de vozes femininas anunciada pela poesia. A subversão está em toda parte, desde a hibridização da forma do romance como herdeiro da épica ocidental até a imersão em um mundo ordenado pelo rigor formal, o soneto clássico.

Assim, a citação completa de sonetos libertos - como o equilibrado em três tercetos de Hilda Hilst (p. 99) e o cuidadosamente desarranjado de Sophia Andresen (p. 227) -, apontam para o controle do autor sobre a forma do romance: a fundação de um lugar ermo, o passado que insiste apesar de todo esforço de esquecimento e a loucura como lugar de reencontro com o mundo abandonado de propósito, como a dizer que só pela loucura é possível habitar a terceira margem.

A cidade cresce e a cada dia é mais difícil conceber um lugar como Jesusalém. A cidade lança suas luzes sobre as sombras, as veredas e as savanas e convida os homens às ilusões da modernidade, ilusões a que todos estamos enlaçados. Este romance de Mia Couto é uma palavra sobre a maior de todas as ilusões: a de esquecer tudo e começar de novo.

Silvestre Vitalício, no afã de criar sua Pasárgada, no delírio pleno de sua loucura e cegueira, não consegue sustentar para os filhos que o mundo acabou. Ouvimos as palavras finais do narrador Mwanito, o afinador de silêncios, a confessar que tem a mesma doença do pai, a cegueira e a loucura. No entanto, pelo amor de uma mulher ele compreende que o mundo ainda nem começou: "A ternura daquela mulher me confirmava que meu pai estava errado: o mundo não morreu. Afinal, o mundo nem chegou a nascer" (p. 277).

E como tudo em Mia Couto se converte em escrita, fiquemos com o livro, na sua concretude transcendente de papel impresso e de letras, para não permitir que o mundo acabe e que cada leitor possa compreender nestas páginas a inauguração ininterrupta de mundos onde a poesia pede para a vida continuar: desdobrando sonetos e afinando silêncios. 